\title{
Insulin resistance and atherosclerosis
}

\author{
Clay F. Semenkovich
}

\author{
Division of Endocrinology, Metabolism, and Lipid Research, Washington University School of Medicine, St. Louis, Missouri, USA.
}

\begin{abstract}
Considerable evidence supports the association between insulin resistance and vascular disease, and this has led to wide acceptance of the clustering of hyperlipidemia, glucose intolerance, hypertension, and obesity as a clinical entity, the metabolic syndrome. While insulin resistance, by promoting dyslipidemia and other metabolic abnormalities, is part of the proatherogenic milieu, it is possible that insulin resistance itself in the vascular wall does not promote atherosclerosis. Recent findings suggest that insulin resistance and atherosclerosis could represent independent and ultimately maladaptive responses to the disruption of cellular homeostasis caused by the excess delivery of fuel.
\end{abstract}

Insulin resistance is strongly associated with atherosclerosis and frequently coexists with common proatherogenic disorders; this relationship is not new. Until the 1700 s, disease was thought to be caused by "humors," a concept dating from the time of Hippocrates. The year 1761 was notable for the publication of $D e$ Sedibus et Causis Morborum per Anatomen Indagatis, a landmark work establishing the anatomic basis of multiple diseases. Using a combination of clinical histories and autopsies, Morgagni identified the association between intraabdominal obesity, hypertension, abnormal metabolism, and extensive atherosclerosis (1). The notion of a syndrome linking metabolic derangements, obesity, and vascular disease went unnoticed until the early 20th century, when Himsworth raised the possibility that insulin insensitivity could have metabolic consequences (2). This was followed by the observation made in the 1950s that hypertriglyceridemia is as common as hypercholesterolemia in individuals with coronary heart disease (3), the discovery by Yalow and Berson in the 1960s that diabetes can occur in the setting of hyperinsulinemia (4), and data from Reaven and colleagues showing that myocardial infarction survivors tend to be insulin resistant and hypertriglyceridemic (5). Associations with low HDL cholesterol and hypertension followed, and Reaven integrated this information in his 1988 Banting Lecture (6) when he coined the term "syndrome X" for the insulin resistance syndrome. This rubric evolved to be known as the metabolic syndrome.

The general thesis received the imprimatur of the National Cholesterol Education Program's Adult Treatment Panel III in 2001 with the establishment of discrete criteria for the metabolic syndrome. Currently, the syndrome is defined by the presence of 3 or more of the following: hypertriglyceridemia $(\geq 150 \mathrm{mg} / \mathrm{dl})$, low HDL cholesterol ( $<50 \mathrm{mg} / \mathrm{dl}$ in women, $<40 \mathrm{mg} / \mathrm{dl}$ in men), hypertension $(\geq 130 / 85 \mathrm{mmHg}$ ), increased waist circumference $(>35$ inches in women, $>40$ inches in men), and elevated fasting glucose $(\geq 100 \mathrm{mg} / \mathrm{dl})$. The WHO has similar criteria that include a prerequisite of diabetes, impaired glucose metabolism, or documented (by hyperinsulinemic-euglycemic clamp) insulin resistance. The syndrome has its own ICD-9 code (277.7), afflicts between $20 \%$ and $25 \%$ of adults in the US alone, and is associated with coronary heart disease (7) as well as increased mortality (8).

Nonstandard abbreviations used: ACE, angiotensin-converting enzyme; $\mathrm{CB}$, cannabinoid; PTP1B, protein tyrosine phosphatase 1B.

Conflict of interest: The author has received lecture fees from Merck and an educational grant from AstraZeneca and has served as a consultant for Pfizer.

Citation for this article: J. Clin. Invest. 116:1813-1822 (2006). doi:10.1172/JCI29024.

\section{Dyslipidemia in insulin resistance}

The lack of appropriate insulin signaling, especially in peripheral tissues such as adipose cells, results in abnormal lipid metabolism that consistently produces a proatherogenic phenotype (Figure 1). Long before people with insulin resistance develop abnormalities of glucose metabolism, circulating FFA levels increase. Impaired insulin signaling leads to loss of suppression of lipolysis (a $G$ proteincoupled process likely mediated by a recently discovered enzyme distinct from hormone-sensitive lipase; ref. 9) and perhaps defective storage of fatty acids in adipocytes (10). The excess provision of lipids from a variety of sources (circulating FFAs originating in fat, endocytosis of triglyceride-rich lipoproteins, and de novo lipogenesis) leads to the posttranslational stabilization of apoB, the major apolipoprotein of VLDL, which enhances the assembly and secretion of VLDL particles (reviewed in ref. 11). Insulin signaling, through PI3K-dependent pathways, also promotes the degradation of apoB. Thus, a combination of excess delivery of fatty acids and limited degradation of apoB explains the hypertriglyceridemia characteristic of insulin resistance. Insulin resistance also decreases lipoprotein lipase activity, the major mediator of VLDL clearance, which may make a smaller contribution to elevated triglycerides in this setting. VLDL is metabolized to remnant lipoproteins and LDL, both strongly associated with atherosclerotic risk. LDL cholesterol levels are usually not elevated in insulin resistance, but remnants are increased and LDL composition is altered. The role of small dense LDL in mediating vascular disease is unresolved.

Increased concentrations of triglyceride-rich VLDL particles contribute to abnormal HDL metabolism in insulin resistance (11). Cholesteryl ester transfer protein mediates the exchange of cholesteryl esters in HDL for triglycerides in VLDL, resulting in cholesteryl ester-enriched VLDL and triglyceride-enriched HDL. The presence of increased triglyceride makes the latter particle a better substrate for hepatic lipase, which may be increased in insulin resistance, and HDL particles decrease because of enhanced metabolism.

A large body of evidence implicates the high-triglyceride, low-HDL phenotype in atherosclerosis (12). Accelerated atherosclerosis in the setting of insulin resistance could thus result from the direct entry of atherogenic VLDL-derived particles into the vasculature, or decreased availability of HDL particles to participate in unloading of cholesterol from the vasculature, known as reverse cholesterol transport.

\section{Hyperglycemia and hypertension}

In addition to fueling potentially proatherogenic dyslipidemia, insulin resistance increases glucose. The lack of insulin signaling decreases transport of glucose into peripheral tissues such 


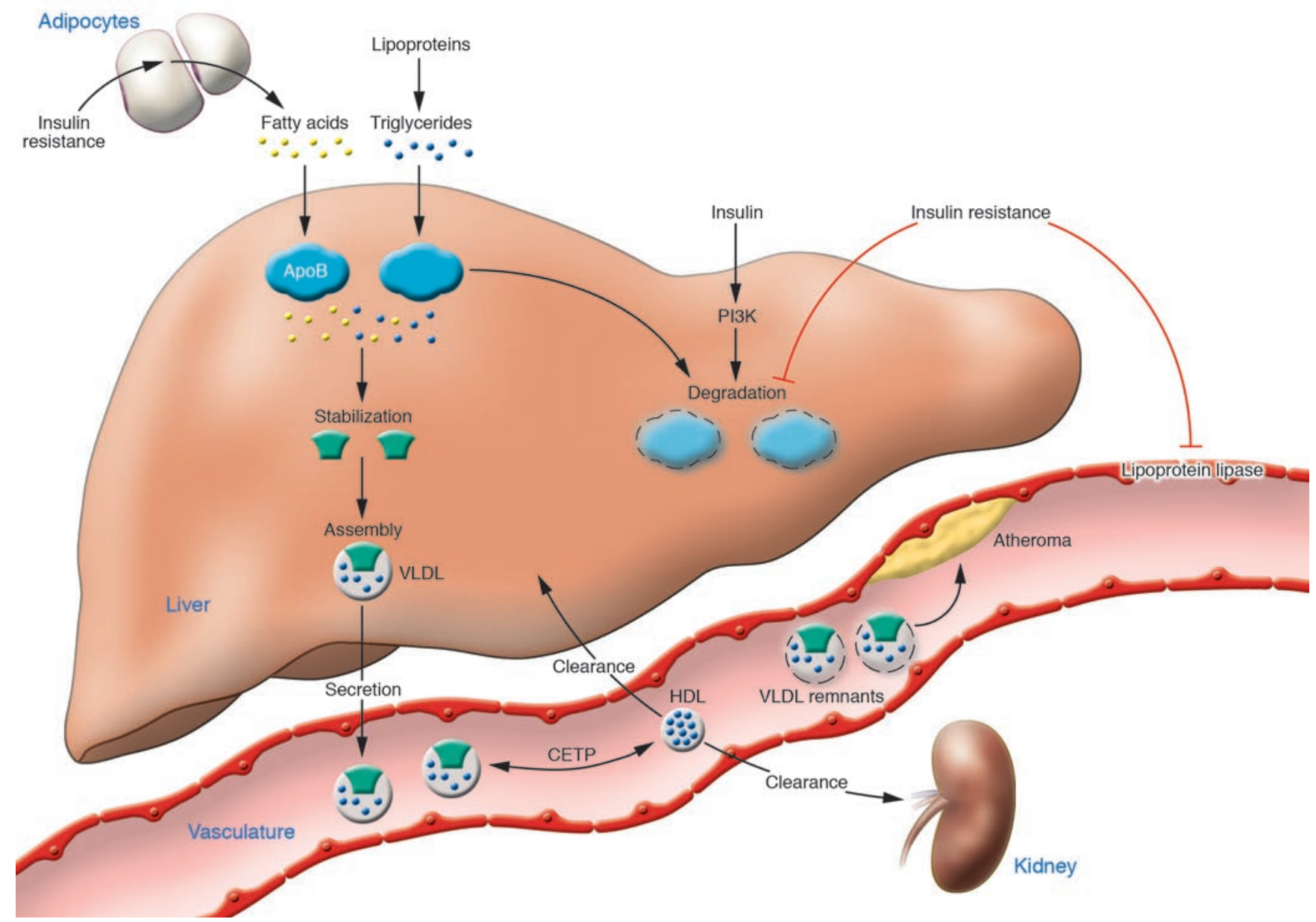

Figure 1

Systemic insulin resistance produces a proatherogenic lipid phenotype. Early in the course of systemic insulin resistance, FFAs increase because of loss of the suppressive effects of insulin on lipolysis in adipocytes. Fatty acids are transported to the liver, where the availability of lipid stabilizes the production of $a p o B$, the major apolipoprotein of VLDL particles. Decreased insulin signaling dampens degradative pathways for apoB, which also contributes to increased VLDL production. Lipoprotein lipase, found in the endothelium of peripheral capillaries and rate-limiting for the clearance of triglyceride-rich lipoproteins, is decreased in insulin resistance. Hence, hypertriglyceridemia in insulin resistance (reflecting elevated VLDL particles) occurs because of a combination of increased VLDL production and decreased VLDL clearance. VLDLs are metabolized to remnant lipoproteins, which can promote atheroma formation. The presence of increased VLDL particles also affects HDL metabolism. Triglycerides in VLDL are transferred to HDL through the action of cholesteryl ester transfer protein (CETP). This process results in a triglyceride-enriched HDL particle that is more rapidly cleared from the circulation, leaving fewer HDL particles to accept cholesterol from the vasculature.

as muscle and fat and increases endogenous glucose production by the liver. Elevated plasma glucose is sensed by the pancreatic $\beta$ cell, which increases insulin secretion to compensate for hyperglycemia, resulting in circulating hyperinsulinemia. With continued stimulation of insulin secretion caused by peripheral insulin resistance, $\beta$ cell hypertrophy occurs, and over time the $\beta$ cell fails to secrete insulin normally (13). The cause of $\beta$ cell dysfunction is unclear, but increased fatty acids, increased glucose, or both may contribute. Ongoing $\beta$ cell failure ultimately leads to type 2 diabetes.

Many people with insulin resistance have elevated levels of glucose, though not to the arbitrary level that constitutes a diagnosis of diabetes. Epidemiologic evidence shows a progressive relationship between cardiovascular disease and glycemia beginning at a fasting glucose level of $70 \mathrm{mg} / \mathrm{dl}$ and a hemoglobin A1C level of $5 \%$, values well below those seen in diabetes $(14,15, \mathrm{~S} 1)$.
The relationship between insulin resistance and hypertension is not as clear. Infusion of fatty acids into the portal vein activates the sympathetic nervous system and elevates blood pressure in rodents (16). Obesity alone is associated with activation of the sympathetic nervous system, which can increase sodium reabsorption (17). Obesity is also associated with elevated leptin levels, which may elevate blood pressure (18). Underappreciated is the fact that intraabdominal obesity in insulin resistance could affect kidney function and blood pressure through direct compressive effects. The prevalence of insulin resistance among patients with hypertension is less than in those with hypertriglyceridemia or hyperglycemia (19).

\section{Beneficial vascular interventions in insulin resistance}

Treating insulin-resistant patients with statins (LDL-lowering agents) or angiotensin-converting enzyme (ACE) inhibitors (blood pressure-lowering agents) decreases atherosclerotic complications. 


\section{Table 1}

Summary of beneficial interventions in insulin resistance

\begin{tabular}{|c|c|c|c|}
\hline Study & Subjects & Treatment & Major outcomes \\
\hline \multicolumn{4}{|c|}{ Statin use in insulin resistance } \\
\hline Heart Protection Study & $\begin{array}{l}\text { Type } 2 \text { diabetes } \\
\text { or vascular disease }\end{array}$ & $\begin{array}{l}\text { Simvastatin } \\
\text { versus placebo }\end{array}$ & $\begin{array}{l}\text { Decrease in vascular events for entire cohort, subset with diabetes, } \\
\text { and those with diabetes and low LDL; decrease in total mortality } \\
\text { for entire group }\end{array}$ \\
\hline CARDS & $\begin{array}{l}\text { Type } 2 \text { diabetes } \\
\text { and no known } \\
\text { vascular disease }\end{array}$ & $\begin{array}{l}\text { Atorvastatin } \\
\text { versus placebo }\end{array}$ & $\begin{array}{l}\text { Decrease in vascular events; nearly significant decrease in total } \\
\text { mortality }(P=0.059)\end{array}$ \\
\hline LIPID trial & $\begin{array}{l}\text { Known vascular } \\
\text { disease }\end{array}$ & $\begin{array}{l}\text { Pravastatin } \\
\text { versus placebo }\end{array}$ & $\begin{array}{l}\text { Decrease in vascular events and total mortality for entire cohort; } \\
\text { decrease in vascular events for subset with impaired fasting glucos }\end{array}$ \\
\hline \multicolumn{4}{|c|}{ Interruption of renin-angiotensin system in insulin resistance } \\
\hline HOPE trial & $\begin{array}{l}\text { Vascular disease } \\
\text { or diabetes }\end{array}$ & $\begin{array}{l}\text { Ramipril } \\
\text { versus placebo }\end{array}$ & $\begin{array}{l}\text { Decrease in vascular events and total mortality for entire cohort; } \\
\text { decrease in vascular events in subset with diabetes; decrease in } \\
\text { new-onset diabetes }\end{array}$ \\
\hline LIFE trial & $\begin{array}{l}\text { Diabetes and } \\
\text { hypertension }\end{array}$ & $\begin{array}{l}\text { Losartan } \\
\text { versus atenolol }\end{array}$ & Fewer vascular events and lower total mortality in losartan group \\
\hline
\end{tabular}

CARDS, Collaborative Atorvastatin Diabetes Study; LIPID, Long-Term Intervention with Pravastatin in Ischemic Disease; HOPE, Heart Outcomes Prevention Evaluation; LIFE, Losartan Intervention for Endpoint Reduction in Hypertension.

These benefits accrue despite the fact that LDL cholesterol levels are not usually elevated in insulin resistance and hypertension is less closely associated with insulin resistance than are other metabolic abnormalities. Results of illustrative trials are shown in Table 1.

The Heart Protection Study $(20,21)$ compared simvastatin with placebo in more than 20,000 adults with either known atherosclerosis or diabetes. Total mortality was significantly decreased in patients receiving statin therapy. In a subset analysis of the 5,348 people with type 2 diabetes in the study, vascular events were significantly decreased with statin therapy. Benefits were seen in the substantial number of these patients with LDL cholesterol levels below $116 \mathrm{mg} / \mathrm{dl}$. The Collaborative Atorvastatin Diabetes Study (CARDS) compared atorvastatin with placebo in 2,838 patients with type 2 diabetes without known atherosclerosis (22). The primary endpoint of vascular events was significantly decreased with statin therapy, and total mortality was nearly significantly decreased with treatment. The Long-Term Intervention with Pravastatin in Ischemic Disease (LIPID) trial was a secondary prevention trial comparing pravastatin with placebo that demonstrated decreased mortality with statin treatment. It included 940 patients with impaired fasting glucose (23), likely an insulin-resistant cohort since mean triglycerides in this group were over $150 \mathrm{mg} / \mathrm{dl}$. Vascular events were significantly decreased in this group.

The Heart Outcomes Prevention Evaluation (HOPE) trial (24) compared the ACE inhibitor ramipril with placebo in over 9,000 patients with either vascular disease or diabetes. Total mortality was decreased in those receiving ramipril. Treatment decreased vascular events among the 3,577 participants with diabetes. Ramipril also decreased the onset of new diabetes, an unexplained observation (suggesting that ACE inhibition causes insulin sensitization that protects the $\beta$ cell from continued hypersecretion) that is also seen in other studies of ACE inhibition (25). The Losartan Intervention for Endpoint Reduction in Hypertension (LIFE) trial compared treatment with an angiotensin receptor blocker (losar$\tan$ ) versus a $\beta$-blocker (atenolol) in over 1,000 patients with diabetes and hypertension (26). Total mortality and the vascular events were decreased in the losartan group.

\section{Rationale for modulating insulin resistance to treat atherosclerosis}

Given the plausible relationships among insulin resistance, lipid metabolism, glucose metabolism, and atherosclerosis, it was reasonable to pursue strategies that would treat insulin resistance itself to address multiple coexisting abnormalities. This approach was supported by several studies showing a relationship between insulin levels and cardiovascular risk. The Paris Prospective Study, which included over 7,000 males (27); a study of over 1,000 males in Finland (28); and the Multiple Risk Factor Intervention Trial (MRFIT) (29) reported positive relationships between insulin levels and atherosclerotic events. However, at least 3 studies in the US (reviewed in ref. 30) failed to confirm this relationship, and 1 actually reported an inverse relationship between insulin levels and vascular disease. More direct support for the involvement of insulin resistance in atherosclerosis came from the Insulin Resistance Atherosclerosis Study (IRAS). This study tested the hypothesis that insulin sensitivity was associated with atherosclerosis and detected an inverse relationship between carotid intima-medial thickness and insulin sensitivity. This finding, however, was tempered by the fact that this relationship between carotid thickness and insulin sensitivity was present in some ethnic groups but not others and was no longer significant after correction for glucose tolerance (31). Recent reports suggest that the metabolic syndrome (with its implied insulin resistance) does not appear to impart vascular disease risk exceeding its components (32). In both the Atherosclerosis Risk in Communities Study and the West of Scotland Coronary Prevention Study (33, S2), vascular disease was related to components of the metabolic syndrome but not uniquely to the syndrome itself. The presence of the metabolic syndrome appears to predict new cases of diabetes but is inferior to the Framingham Risk Score as a predictor of clinical events related to atherosclerosis $(34$, S2).

A concrete conceptual framework for developing new therapies was provided by the discovery of PPARs in the early 1990s. PPARs (37) are ligand-activated nuclear receptors that form heterodimers with the retinoid $\mathrm{X}$ receptor to affect the expression of genes involved in lipid metabolism, glucose metabolism, and 
Table 2

Summary of trials using PPAR activation

\begin{tabular}{|c|c|c|}
\hline Study & Agonist & Major outcomes \\
\hline \multicolumn{3}{|l|}{ PPAR $\alpha$ agonists } \\
\hline WHO cooperative trial & Clofibrate & $\begin{array}{l}\text { Decrease in coronary events in this primary prevention trial; no effect on vascular disease death; } \\
\text { increase in total mortality }(P<0.01)\end{array}$ \\
\hline Helsinki Heart Study & Gemfibrozil & $\begin{array}{l}\text { Decrease in vascular events and vascular death in this primary prevention trial; no effect on total } \\
\text { mortality (rate [per 1,000]: } 21.9 \text { for gemfibrozil, } 20.7 \text { for placebo) }\end{array}$ \\
\hline VA-HIT & Gemfibrozil & $\begin{array}{l}\text { Decrease in vascular events in this secondary prevention trial; nearly significant decrease in vascula } \\
\text { death }(P=0.07) \text {; no effect on total mortality }(9.9 \% \text { deaths for gemfibrozil, } 10.9 \% \text { deaths for plac }\end{array}$ \\
\hline BIP study & Bezafibrate & $\begin{array}{l}\text { No effect on vascular events; apparent benefit in post hoc analysis of subset of patients with } \\
\text { triglycerides over } 200 \mathrm{mg} / \mathrm{dl} \text {; no effect on total mortality ( } 10.4 \% \text { deaths for bezafibrate, } \\
9.9 \% \text { deaths for placebo) }\end{array}$ \\
\hline FIELD study & Fenofibrate & $\begin{array}{l}\text { No effect on primary endpoint of coronary events; decreased secondary endpoint of total } \\
\text { cardiovascular events }(P=0.035) \text {; nonsignificant increase in coronary heart disease mortality } \\
\text { and total mortality (rate: } 14.2 \text { for fenofibrate, } 12.9 \text { for placebo) }\end{array}$ \\
\hline \multicolumn{3}{|l|}{ PPAR $\gamma$ agonist } \\
\hline PROACTIVE & Pioglitazone & $\begin{array}{l}\text { No effect on primary endpoint of all vascular events in this secondary prevention trial; decreased } \\
\text { secondary endpoint of death, nonfatal myocardial infarction, CVA }(P=0.027) \text {; no effect on total } \\
\text { mortality with fewer overall deaths in pioglitazone group }\end{array}$ \\
\hline
\end{tabular}

VA-HIT, Veterans Affairs High-Density Lipoprotein Cholesterol Intervention Trial; BIP, Bezafibrate Infarction Prevention; FIELD, Fenofibrate Intervention and Event Lowering in Diabetes; PROACTIVE, Prospective Pioglitazone Clinical Trial in Macrovascular Events.

inflammation. Their potential role in insulin resistance is logical, since their endogenous ligands are postulated to be fatty acids. The first PPAR identified, PPAR $\alpha$, is the target of fibrates, drugs known to lower triglycerides and increase HDL cholesterol, 2 of the defining components of the metabolic syndrome. PPAR $\gamma$ is the target of thiazolidinediones, drugs that lower glucose and substantially enhance insulin sensitivity.

For both PPAR $\alpha$ and PPAR $\gamma$, data support the concept that pharmacologic activation of these receptors provides vascular benefits. Treatment of insulin-resistant $o b / o b$ mice and Zucker diabetic rats with a PPAR $\alpha$ agonist decreased adiposity and lowered insulin levels (36). Clamp studies in a lipoatrophic mouse model showed enhanced insulin sensitivity at the liver with PPAR $\alpha$ agonist treatment (37). Administration of a PPAR $\alpha$ activator to mice, especially in the presence of a transgene for apoA-I (a major component of HDL), decreased experimental atherosclerosis (38). One study in humans reported a decreased incidence of new cases of type 2 diabetes in insulin-resistant patients treated with bezafibrate, suggesting that PPAR $\alpha$ activation would enhance insulin sensitivity (39). Treatment of male LDL receptor-null mice with 2 different PPAR $\gamma$ agonists or the PPAR $\alpha$-specific agonist GW7647 decreased experimental atherosclerosis and inhibited foam cell formation $(40,41)$. In another mouse model, PPAR $\alpha$ but not PPAR $\gamma$ agonists decreased atherosclerosis (42).

\section{Modulation of PPARs and insulin sensitivity in humans}

Despite these encouraging results, findings with PPAR activation in humans to treat atherosclerosis have been mixed (Table 2). Several studies have used PPAR $\alpha$ agonists to decrease vascular endpoints. The first, the WHO cooperative trial on primary prevention of ischemic heart disease, used clofibrate. Initial results reported in 1978 showed a significant decrease in nonfatal myocardial infarction but no significant effect on death from ischemic heart disease (43). However, follow-up studies published in 1980 and 1984 revealed significant increases in total mortality in those treated with clofibrate $(44,45)$. No specific cause of death could be identified. This unsettling observation has not yet been explained.

The Helsinki Heart Study used another fibrate, gemfibrozil, and reported decreased myocardial infarctions and cardiac death with treatment (46). Overall, there were 45 deaths with gemfibrozil and 42 with placebo. In the Veterans Affairs High-Density Lipoprotein Cholesterol Intervention Trial (VA-HIT), gemfibrozil also decreased myocardial infarctions and nearly significantly decreased death due to coronary heart disease (47). Overall, there were 198 deaths with gemfibrozil and 220 with placebo. A larger study of patients with similar lipid characteristics, the Bezafibrate Infarction Prevention (BIP) study, used a different fibrate and found no significant effect of PPAR $\alpha$ activation on cardiac endpoints (48). Overall, there were 161 deaths with bezafibrate and 152 with placebo. Very recently, the Fenofibrate Intervention and Event Lowering in Diabetes (FIELD) study compared the effects of fenofibrate and placebo in 9,795 patients with type 2 diabetes, some with previous cardiovascular disease but most without. Fenofibrate lowered triglycerides as well as LDL cholesterol and elevated HDL cholesterol, all potentially beneficial, but did not decrease the number of patients reaching the primary endpoint of coronary events (49). Several adverse endpoints appeared to be more likely with PPAR $\alpha$ activation in this insulin-resistant cohort. Overall, there were 356 deaths with fenofibrate and 323 with placebo. Interpretation of this study is complicated by differential use of statins in the study groups (51).

Currently, the results of 1 clinical study that address the role of PPAR $\gamma$ activation in atherosclerotic endpoints are available. The

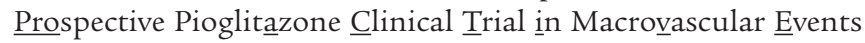
(PROACTIVE) was a secondary prevention trial that compared the effects of pioglitazone and placebo in 5,238 patients with type 2 diabetes and known vascular disease (50). The use of this insulin sensitizer lowered glucose as well as triglycerides, elevated HDL cholesterol, and lowered blood pressure but failed to affect the 


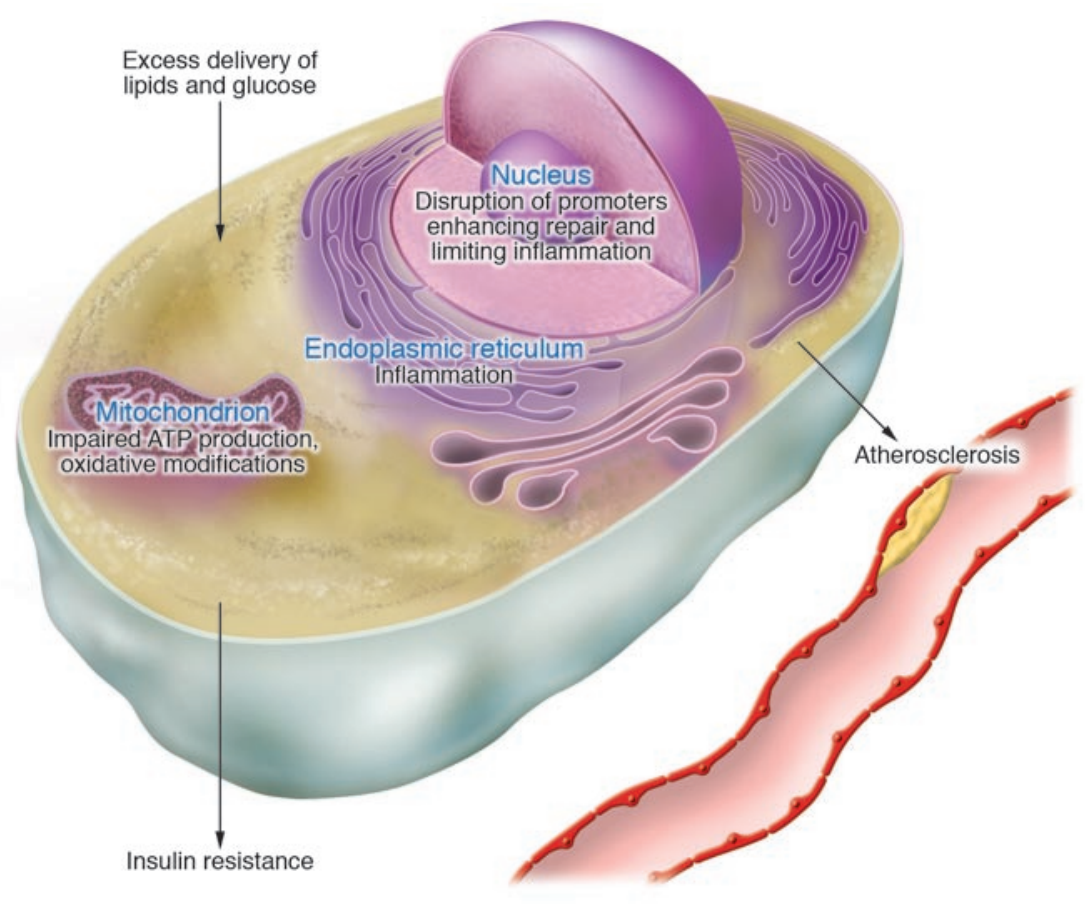

\section{Figure 2}

Nutrient excess, organelle stress, and the development of atherosclerosis and insulin resistance. The excess delivery of glucose, lipids, and other nutrients disrupts homeostasis at key organelles, leading to genomic and ER stress. Increased fuel flow is associated with increased mitochondrial metabolism with the potential for excessive generation of reactive oxygen species, leading to mitochondrial dysfunction. The nuclear genome may be affected by oxidative modifications and by structural alterations due to the accumulation of intracellular lipids, both of which may disrupt repair mechanisms as well as transcriptional responses that minimize inflammatory damage. Excessive demand on the ER induces stress responses that lead to inflammation. Genomic and ER stress could be adaptive in the short term, since decreased insulin signaling would limit additional uptake of nutrients and increased macrophage activation would clear toxic lipids. However, these independent processes stimulated by organelle stress ultimately become maladaptive in the setting of continued nutrient excess. number of patients reaching the primary endpoint of any cardiovascular event plus total mortality. Overall, there were 177 deaths with pioglitazone and 186 with placebo. There was a beneficial effect in terms of the secondary endpoint (a composite of mortality, nonfatal myocardial infarction, and stroke), but pioglitazone also increased body weight, LDL cholesterol levels, and heart failure. $\operatorname{PPAR} \gamma$ activation promotes the storage of lipid in fat cells; lowering of triglycerides reflects the conversion of VLDL particles to LDL particles; and glitazones accelerate sodium absorption at the renal collecting duct $(51,52)$ to expand plasma volume and increase the risk for heart failure. Enhanced reabsorption of sodium has been known for decades to accompany insulin action (53).

Dual agonists affecting PPAR $\alpha$ (to lower triglycerides and increase HDL cholesterol) and PPAR (to lower glucose) have been generated in hopes of treating the metabolic syndrome and insulin resistance. These drugs appear to have an undesirably high incidence of atherosclerosis-related events (54).

One interpretation of these results is that activation of PPARs with current agents may not provide robust cardiovascular benefit. It also appears that therapies directed at lowering glucose in people with insulin resistance may not provide striking benefits. Lowering glucose with sulfonylureas or insulin in the United Kingdom Prospective Diabetes Study did not result in a statistically significant benefit in terms of atherosclerotic endpoints. Treatment of a subset of obese patients with the insulin sensitizer metformin, which has complex effects including activation of AMP kinase, decreased aggregate macrovascular events compared with conventional therapy (55). Curiously, the addition of metformin treatment to sulfonylurea treatment increased the patients' risk of diabetes-related death (55).

\section{Potential strategies in development}

Pharmacologically reversing insulin resistance in people with obesity and diabetes may ultimately be shown to decrease vascular disease. However, approaches to alleviating insulin resistance (especially in the absence of therapeutic lifestyle interventions that involve achieving a negative energy balance) may actually accelerate atherosclerosis. Antagonism of cannabinoid-1 (CB1) receptors is one strategy that may be used in treating patients with insulin resistance. CB1 receptors are generally found in the brain, and their activation has complex effects on feeding, metabolism, and addictive behaviors. CB2 receptors are found on immune cells including monocytes, a critical cell in atherosclerosis. Rimonabant is a CB1 receptor blocker that appears to improve features of the metabolic syndrome and bring about favorable changes in markers for insulin resistance (56, S3), albeit with side effects that include nausea, depression, and anxiety. The pharmacology of drugs that interact with these receptors is complex, and CB1 antagonists have also been shown to have inverse agonist activity at CB2 receptors (57). Since activation of CB2 receptors (which are abundant in human and mouse atherosclerotic lesions) decreases atherosclerosis and macrophage activation in mice (58), it is possible that, like the use of other agents directed toward insulin resistance, CB1 blockade could improve parameters associated with insulin resistance without decreasing atherosclerotic complications.

While several types of vascular cells are involved in atherosclerosis, the monocyte/macrophage appears to be central to the initiation and evolution of the vascular lesion. Inactivation of monocyte chemoattractant protein-1, a potent chemokine agonist for monocytes, or its receptor CCR2 decreases vascular disease in mice $(59,60)$. Mice with defects in the differentiation of monocytes into macrophages because of M-CSF deficiency are protected from atherosclerosis (61). Macrophage development is also controlled in part by protein tyrosine phosphatase $1 \mathrm{~B}$ (PTP1B). PTP1B, an ER-based phosphatase that causes insulin resistance by reversing tyrosine phosphorylation of the insulin receptor and decreasing downstream PI3K activity (62), suppresses macrophage development and activation (63). Inactivation of PTP1B enhances insulin sensitivity in mice, an observation that has prompted the search for small-molecule inhibitors of this phosphatase. One prediction 
is that these agents would lower glucose and lipid levels but promote the activation and development of macrophages, which would accelerate atherosclerosis or perhaps nullify vascular benefits of improved glucose and lipid profiles.

\section{Could insulin resistance in the vasculature be beneficial?}

Since current pharmacologic therapies aimed at decreasing insulin resistance do not yet appear to provide large decreases in atherosclerotic complications, could it be that insulin resistance in the vasculature is actually a beneficial adaptive response? There is precedent for dampening hormone signaling in response to stress. With both chronic illness in the outpatient setting and severe illness in hospitalized patients, levels of triiodothyronine (the active form of thyroid hormone) decrease (64). Administration of thyroid hormone in the setting of illness has not been shown to improve outcomes $(65, \mathrm{~S} 4)$, and there is evidence suggesting that the low-thyroid state could be a beneficial adaptive response in terms of protein catabolism (66).

Expression of the inflammatory cytokine TNF- $\alpha$ is increased in obesity and causes insulin resistance by interfering with tyrosine phosphorylation of the insulin receptor as well as insulin receptor substrate-1 (IRS-1) (67). Given the inflammatory nature of atherosclerosis, most have assumed that TNF- $\alpha$ is proatherogenic, but inactivation of one of the receptors for this cytokine in mice increases atherosclerosis (68). TNF- $\alpha$ increases macrophage expression of a key protein responsible for unloading cholesterol and presumably limiting atherosclerosis, ATP-binding cassette-A1, in a manner that appears to be dependent on NF- $\mathrm{BB}$, a transcription factor that coordinates inflammatory responses (69). These results are consistent with the observation that inactivation of NF- $\mathrm{BB}$ increases vascular disease in mice (70) and raise the possibility that the vasculature may attempt to limit the acquisition of cholesterol through processes related to insulin resistance.

Insulin resistance is the consequence of disruption of signaling pathways initiated by the tyrosine kinase activity of the insulin receptor. There is abundant cross-talk between signals generated by the insulin receptor and other growth factor receptors such as PDGFR that converge on MAPK pathways (71). Both the insulin receptor and PDGFR ultimately cause phosphorylation of Shc, although with different time courses (72). Both associate with PTP1B (73), the phosphatase that dampens signaling. PDGF, like insulin, is capable of stimulating glucose transport when sufficient PDGFRs are present (74). Imatinib, a tyrosine kinase inhibitor that affects a number of targets including PDGFR, the KIT receptor, and BCR-ABL (S5), decreases cholesterol-induced atherosclerosis in a model of accelerated smooth muscle migration (75). Thus, global resistance to growth factor signaling that might occur in the setting of insulin resistance could serve to attenuate vascular disease.

Systemic insulin resistance, which increases levels of glucose and lipids, is not desirable. However, insulin resistance in cells directly relevant to atherosclerosis may have different effects. Conflicting data address this issue in mouse models. Inactivation of the insulin receptor in cells of myeloid lineage decreases atherosclerosis in apoE-null mice (76). Macrophage deficiency of IRS-2, the major insulin receptor substrate in this cell type, also decreases vascular disease in apoE-null mice (76), suggesting that vascular insulin resistance could be beneficial. In another model, LDL receptor-null mice, macrophage deficiency of the insulin receptor had no effect on initial lesion formation (77). However, lesions in these animals became more complex at later time points because of accelerated apoptosis occurring in the setting of increased ER stress (see below). These data suggest that insulin resistance could have differential effects on lesion initiation, propagation, and plaque rupture.

PI3Ks, enzymes that generate phosphorylated lipid signaling molecules after stimulation by the insulin receptor and other receptors, exist in several isoforms. PI3K $\gamma$ is found in hematopoietic cells, especially monocytes and macrophages, and its inhibition by small molecules has beneficial effects on inflammation in addition to lifespan in models of systemic lupus and rheumatoid arthritis $(78,79)$, diseases associated with accelerated atherosclerosis. Modulation of the activity of this kinase in appropriate models of vascular disease could help clarify the role of insulin signaling in vascular disease.

\section{Mitochondrial stress}

An alternative view of the relationship between insulin resistance and atherosclerosis is that they share a common etiology but each follows an independent course. The common etiology may be organelle stress in response to nutrient excess occurring in mitochondria, the nucleus, and the ER (Figure 2).

Mitochondria are the major source of ATP production in animals. Production of ATP results in the production of reactive oxygen species as electrons are transferred from nutrients to molecular oxygen. This process, known as respiration, takes place at the inner mitochondrial membrane and is responsible for most of the generation of reactive oxygen species such as superoxide that are implicated in atherosclerosis. In addition to its proximity to reactive oxygen species, the mitochondrial genome may be particularly susceptible to oxidative damage because of its lack of histones and a deficient mismatch repair system. This combination could be responsible for heteroplasmy, the presence of both normal and mutated mitochondrial DNA in tissues (80). Mitochondrial dysfunction may be involved in skeletal muscle insulin resistance. Expression of genes critical for mitochondrial function, such as the gene encoding PGC-1 $\alpha$, is decreased in humans with insulin resistance (81). Energy production is impaired in the muscle of insulin-resistant subjects (82). Recent findings also implicate mitochondrial dysfunction in atherosclerosis.

As is noted above, insulin resistance causes circulating fatty acids to increase. Increased oxidation of fatty acids by aortic endothelial cells was recently reported to accelerate production of superoxide by the mitochondrial electron transport chain (83). This effect was associated with proatherogenic vascular effects, and prevented by either blocking of the release of fatty acids from adipose tissue or inhibition of mitochondrial fatty acid oxidation, consistent with a role for increased mitochondrial metabolism in vascular disease.

Human atherosclerotic samples obtained during vascular surgery show greater mitochondrial DNA damage than nonatherosclerotic samples obtained from age-matched transplant donors (84). Mitochondrial damage precedes the development of atherosclerosis and tracks with lesion extent in apoE-null mice, and mitochondrial dysfunction caused by heterozygous deficiency of a superoxide dismutase (SOD2) increases atherosclerosis and vascular mitochondrial damage in the same model (84).

Blood vessels destined to develop atherosclerosis may be characterized by inefficient ATP production due to the uncoupling of respiration and oxidative phosphorylation. Blood vessels have regions of hypoxia (85), which is known to lower the ratio of state 3 (phosphorylating) to state 4 (nonphosphorylating) respiration (S6). The 
Table 3

DNA damage disorders associated with insulin resistance and atherosclerosis

$\begin{array}{lr}\begin{array}{l}\text { Syndrome } \\ \text { Hutchinson-Gilford progeria }\end{array} & \begin{array}{c}\text { Molecular defect } \\ \text { De novo point mutation in lamin A } \\ \text { gene resulting in truncated protein } \\ \text { Mutation in WRN, a DNA helicase }\end{array} \\ \text { Ataxia telangiectasia } & \begin{array}{r}\text { Defect in ATM, a protein kinase } \\ \text { with p53 as a substrate }\end{array} \\ \text { Cockayne } & \text { Mutations in CSA and CSB, } \\ & \text { involved in DNA repair }\end{array}$

Syndrome

din DNA repair

\section{Phenotype}

Atherosclerosis, insulin resistance, hyperglycemia, growth retardation, lipodystrophy, osteoporosis, hair and skin abnormalities

Atherosclerosis, malignancies, insulin resistance, central adiposity, dyslipidemia, autoimmunity, osteoporosis

Cerebellar ataxia, skin and eye telangiectasias, malignancies, immune deficiency, impaired growth, insulin resistance, atherosclerosis in heterozygotes

Neurodegeneration, ataxia and mental retardation, atherosclerosis, insulin resistance, dyslipidemia, impaired growth presence of abnormal mitochondria in smooth muscle cells is an early signal of human atherosclerosis (S7). Atherosclerosis-susceptible pigeons have uncoupled mitochondrial respiration at lesionprone sites (86). Human atherosclerotic lesions have been known for decades to be deficient in essential fatty acids (87), a condition that causes respiratory uncoupling (88, S8) and atherosclerosis (89).

The inducible expression of uncoupling protein 1 (UCP1), the prototypical inner mitochondrial membrane anion transporter found in brown fat, in the vasculature increases atherosclerosis and several markers of oxidative damage in apoE-null mice (90). Mitochondrial dysfunction resulting from UCP1 expression in blood vessels causes renin-dependent hypertension (90), and a mitochondrial mutation associated with hypertension has been described in humans (91). Uncoupling increases respiration, which might account for evidence of increased oxidative modifications. For reasons that are unclear, brown fat, the tissue defined by respiratory uncoupling, encases chest and neck blood vessels in humans (92).

Most fatty acid oxidation, which is promoted by PPAR $\alpha$ activation, occurs in mitochondria. Mitochondrial effects could explain why PPAR $\alpha$-deficient mice are protected from diet-induced insulin resistance and atherosclerosis (93) as well as glucocorticoid-induced insulin resistance and hypertension (94). Caloric restriction, which improves features of insulin resistance, increases mitochondrial biogenesis and, surprisingly, enhances the efficiency of ATP production $(95,59)$. Dysfunctional mitochondria in cultured cells can be rescued by transfer of mitochondria from adult stem cells (96), raising the possibility of restoration of normal bioenergetics in the vasculature to treat atherosclerosis associated with insulin resistance.

\section{Nuclear stress}

Genomic stress, an alteration of DNA structure or function frequently caused by oxidative modifications, is another likely contributor to both atherosclerosis and insulin resistance. Both atherosclerosis and insulin resistance are manifestations of aging, a process characterized by accumulation of DNA damage. Different regions of the genome appear to manifest differential susceptibility to DNA damage. The promoters, but not the coding regions, of downregulated genes in the aging human brain have striking increases in the oxidation product 8-oxoguanine, and many genes are upregulated, generally those involved in antioxidant effects, DNA repair, and stress responses (97). It is plausible that genes specifically involved in maintenance of vascular integrity and insulin sensitivity are preferentially affected by oxidative damage.

Several well-described disorders are consistent with this premise (Table 3). Children with Hutchinson-Gilford progeria syndrome have insulin resistance and usually die before the age of 15 from coronary or peripheral vascular disease $(98,99)$. A progressive smooth muscle cell defect characterizes mice carrying the mutation most commonly found in humans (100). Progeroid disorders are associated with the accumulation of a farnesylated form of prelamin A that disrupts DNA repair (101), and clinical features are ameliorated in mice with a drug that inhibits farnesylation (102). Statins, inhibitors of HMG-CoA reductase, also decrease farnesylation, which could implicate enhanced genomic maintenance in the benefit people with diabetes derive from statins even when cholesterol levels are low (21). Patients with Werner syndrome, caused by a mutation in a DNA helicase (103), have insulin resistance and vascular disease in addition to other serious problems, including malignancies $(104,105)$. Ataxia telangiectasia is particularly interesting, because the protein mutated in this disease, ATM, is a kinase that activates the tumor suppressor p53 (106). p53 is found in atherosclerotic lesions from humans and rabbits $(107,108)$, and p53-null mice have accelerated atherosclerosis $(109,110)$. The protein most commonly mutated in Cockayne syndrome, CSB, appears to be involved in multiple processes, including transcription, nucleotide excision repair, and base excision repair (111). The mechanisms by which DNA maintenance defects in these disorders lead to atherosclerosis and insulin resistance are unknown.

\section{ER stress}

ER stress also represents a potential common etiology for insulin resistance and atherosclerosis. Both dietary and genetic models of obesity disrupt normal protein folding in the ER, leading to stress signals mediated in part by JNK (112). One of the JNK isoforms, JNK2, has been shown to be proatherogenic in macrophages (113), and cholesterol trafficking to the ER activates JNK2 in macrophages (114). Saturated fatty acids may induce ER stress (115). Recent data are consistent with lipid loading causing ER stress, which induces cleavage of the ER-bound transcription factor CREBH, allowing this activated protein to migrate to the nucleus and produce a systemic inflammatory response by increased expression of acutephase response genes (116). As is noted above, deficiency of the insulin receptor in macrophages increases the ER stress response and apoptosis in a mouse model of atherosclerosis (77).

\section{Additional potential mechanisms}

Surprising results from long-term follow-up of type 1 diabetes subjects in the Diabetes Control and Complications Trial suggest that glucose control may provide vascular-disease benefits exceeding those 
achieved with lipid and blood pressure lowering (117). These benefits are particularly interesting because they were seen in individuals who were subjected to a remote period of intense glucose control, implying that the vasculature has "memory," with adverse events perhaps reflecting metabolic states from years before. It is unclear whether this effect represents decreased initiation of lesions during the period of optimal control that is reflected years later as these lesions propagate. If this is relevant to insulin resistance, individuals could show benefits years after periods of optimal glucose control. One potential explanation is that these periods of improved glucose control alter the host/bacteria relationship. Periodontal disease is common in diabetes (118) and has been linked to atheroma formation in humans (119), and colonization of mice with a periodontal disease pathogen promotes atherosclerosis (120), perhaps through an interaction with TLR2 and TLR4 (proatherogenic components of the innate immune system). Intestinal bacteria appear to control nutrient processing and modulate body composition in mice (121).

The mouse may not be an optimal model for examining the effects of glucose on atherosclerosis, but recent findings indicate that the enzyme aldose reductase, long thought to be involved in some microvascular complications of hyperglycemia, accelerates vascular disease in this species (122). It may be possible to inhibit this pathway to treat atherosclerosis (123) in people with insulin resistance.

Fatty acids are central to the metabolic disturbances that characterize insulin resistance and atherosclerosis, in part because they drive increased production of lipoproteins by the liver. In addition to delivering lipids to macrophages to induce cellular stress, these lipid particles may modulate the immune system to promote atherosclerosis. Hyperlipidemia appears to promote the retention of apoptotic debris in the vasculature, thereby enhancing the inflammatory response (124). ApoE (a key component of VLDL particles elevated in insulin resistance) appears to be capable of efficiently activating $T$ cells by delivering lipid antigens, which likely participate in atherosclerosis, to CD1 molecules (125).

\section{Conclusions}

Insulin resistance appears to be a simple but deceptive explanation for the development of atherosclerosis in people with obesity and diabetes. Systemic insulin resistance has proatherogenic effects. But treatment with insulin sensitizers to decrease vascular disease has yielded mixed results, perhaps because insulin resistance in the vasculature may not promote atherosclerosis. Until the mechanisms underlying insulin resistance and atherosclerosis are better understood, optimal therapy for overweight patients at risk for vascular disease should include interventions easy to recommend and difficult to realize: eat less and exercise more.

Note: References S1-S9 are available online with this article; doi:10.1172/JCI29024DS1.

Address correspondence to: Clay F. Semenkovich, Washington University School of Medicine, St. Louis, Missouri 63110, USA. Phone: (314) 362-4454; Fax: (314) 362-7641; E-mail: csemenko@wustl.edu.
1. Enzi, G., Busetto, L., Inelmen, E.M., Coin, A., and Sergi, G. 2003. Historical perspective: visceral obesity and related comorbidity in Joannes Baptista Morgagni's 'De sedibus et causis morborum per anatomen indagata.' Int. J. Obes. Relat. Metab. Disord. 27:534-535.

2. Himsworth, H. 1939. The mechanism of diabetes mellitus. III. Human diabetes mellitus. Lancet. 2:171-175.

3. Albrink, M.J., and Mann, E.B. 1958. Serum triglycerides in coronary artery disease. Trans. Assoc. Am. Physicians. 71:162-173.

4. Yalow, R.S., and Berson, S.A. 1960. Immunoassay of endogenous plasma insulin in man. J. Clin. Invest. 39:1157-1175.

5. Reaven, G., Calciano, A., Cody, R., Lucas, C., and Miller, R. 1963. Carbohydrate intolerance and hyperlipemia in patients with myocardial infarction without known diabetes mellitus. J. Clin. Endocrinol. Metab. 23:1013-1023.

6. Reaven, G.M. 1988. Banting lecture 1988. Role of insulin resistance in human disease. Diabetes. 37:1595-1607.

7. Alexander, C.M., Landsman, P.B., Teutsch, S.M., and Haffner, S.M. 2003. NCEP-defined metabolic syndrome, diabetes, and prevalence of coronary heart disease among NHANES III participants age 50 years and older. Diabetes. 52:1210-1214.

8. Malik, S., et al. 2004. Impact of the metabolic syndrome on mortality from coronary heart disease, cardiovascular disease, and all causes in United States adults. Circulation. 110:1245-1250.

9. Villena, J.A., Roy, S., Sarkadi-Nagy, E., Kim, K.H., and Sul, H.S. 2004. Desnutrin, an adipocyte gene encoding a novel patratin domain-containing protein, is induced by fasting and glucocorticoids: ectopic expression of desnutrin increases triglyceride hydrolysis. J. Biol. Chem. 279:47066-47075.

10. Foley, J.E. 1992. Rationale and application of fatty acid oxidation inhibitors in treatment of diabetes mellitus. Diabetes Care. 15:773-784.

11. Ginsberg, H.N. 2006. Review: efficacy and mecha- nisms of action of statins in the treatment of diabetic dyslipidemia. J. Clin. Endocrinol. Metab. 91:383-392.

12. Szapary, P.O., and Rader, D.J. 2004. The triglyceride-high-density lipoprotein axis: an important target of therapy? Am. Heart J. 148:211-221.

13. Cavaghan, M.K., Ehrmann, D.A., and Polonsky, K.S. 2000. Interactions between insulin resistance and insulin secretion in the development of glucose intolerance. J. Clin. Invest. 106:329-333.

14. Coutinho, M., Gerstein, H.C., Wang, Y., and Yusuf, S. 1999. The relationship between glucose and incident cardiovascular events. A metaregression analysis of published data from 20 studies of 95,783 individuals followed for 12.4 years. Diabetes Care. 22:233-240.

15. Khaw, K.T., et al. 2004. Association of hemoglobin A1c with cardiovascular disease and mortality in adults: the European prospective investigation into cancer in Norfolk. Ann. Intern. Med. 141:413-420.

16. Grekin, R.J., Vollmer, A.P., and Sider, R.S. 1995. Pressor effects of portal venous oleate infusion. A proposed mechanism for obesity hypertension. Hypertension. 26:193-198.

17. Morse, S.A., Zhang, R., Thakur, V., and Reisin, E. 2005. Hypertension and the metabolic syndrome. Am. J. Med. Sci. 330:303-310.

18. Bernal-Mizrachi, C., et al. 2002. Respiratory uncoupling lowers blood pressure through a leptindependent mechanism in genetically obese mice. Arterioscler. Thromb. Vasc. Biol. 22:961-968.

19. Bonora, E., et al. 1998. Prevalence of insulin resistance in metabolic disorders: the Bruneck Study. Diabetes. 47:1643-1649.

20. Heart Protection Study Collaborative Group. 2002. MRC/BHF Heart Protection Study of cholesterol lowering with simvastatin in 20,536 high-risk individuals: a randomized placebo-controlled trial. Lancet. 360:7-22.

21. Collins, R., Armitage, J., Parish, S., Sleigh, P., and Peto, R. 2003. MRC/BHF Heart Protection Study of cholesterol-lowering with simvastatin in 5,963 people with diabetes: a randomised placebo-controlled trial. Lancet. 361:2005-2016.

22. Colhoun, H.M., et al. 2004. Primary prevention of cardiovascular disease with atorvastatin in type 2 diabetes in the Collaborative Atorvastatin Diabetes Study (CARDS): multicentre randomized placebocontrolled trial. Lancet. 364:685-696.

23. Keech, A., et al. 2003. Secondary prevention of cardiovascular events with long-term pravastatin in patients with diabetes or impaired fasting glucose. Diabetes Care. 26:2713-2721.

24. Yusuf, S., et al. 2000. Effects of an angiotensin-converting-enzyme inhibitor, ramipril, on cardiovascular events in high-risk patients. N. Engl. J. Med. 342:145-153.

25. Hansson, L., et al. 1999. Effect of angiotensinconverting-enzyme inhibition compared with conventional therapy on cardiovascular morbidity and mortality in hypertension: the Captopril Prevention Project (CAPP) randomized trial. Lancet. 353:611-616.

26. Lindholm, L.H., et al. 2002. Cardiovascular morbidity and mortality in patients with diabetes in the Losartan Intervention for Endpoint reduction in hypertension study (LIFE): a randomized trial against atenolol. Lancet. 359:1004-1010.

27. Ducimetiere, P., et al. 1980. Relationship of plasma insulin levels to the incidence of myocardial infarction and coronary heart disease mortality in a middle-aged population. Diabetologia. 19:205-210.

28. Pyorala, K. 1979. Relationship of glucose tolerance and plasma insulin to the incidence of coronary heart disease: results from two population studies in Finland. Diabetes. 2:131-141.

29. Orchard, T.J., et al. 1994. Insulin as a predictor of coronary heart disease: interaction with apolipoprotein E phenotype. A report from the Multiple Risk Factor Intervention Trial. Ann. Epidemiol. 4:40-45.

30. Wingard, D.L., Barrett-Connor, E.L., and Ferrara, A. 1995. Is insulin really a heart disease risk factor? Diabetes Care. 18:1299-1304. 
31. Howard, G., et al. 1996. Insulin sensitivity and atherosclerosis. The Insulin Resistance Atherosclerosis Study (IRAS) Investigators. Circulation. 93:1809-1817.

32. Kahn, R., Buse, J., Ferrannini, E., and Stern, M. 2005. The metabolic syndrome: time for a critical appraisal. Joint statement from the American Diabetes Association and the European Association for the Study of Diabetes. Diabetes Care. 28:2289-2304.

33. McNeill, A.M., et al. 2005. The metabolic syndrome and 11-year risk of incident cardiovascular disease in the Atherosclerosis Risk in Communities study. Diabetes Care. 28:385-390.

34. Wannamethee, S.G., Shaper, A.G., Lennon, L., and Morris, R.W. 2005. Metabolic syndrome vs Framingham Risk Score for prediction of coronary heart disease, stroke, and type 2 diabetes mellitus. Arch. Intern. Med. 165:2644-2650.

35. Berger, J.P., Akiyama, T.E., and Meinke, P.T. 2005. PPARs: therapeutic targets for metabolic disease. Trends Pharmacol. Sci. 26:244-251.

36. Guerre-Millo, M., et al. 2000. Peroxisome proliferative-activated receptor alpha activators improve insulin sensitivity and reduce adiposity. J. Biol. Chem. 275:16638-16642.

37. Chou, C.J., et al. 2002. WY14,643, a peroxisome proliferative-activated receptor alpha (PPARalpha) agonist, improves hepatic and muscle steatosis and reverses insulin resistance in lipoatrophic A-Zip/F-1 mice. J. Biol. Chem. 277:24484-24489.

38. Duez, H., et al. 2002. Reduction of atherosclerosis by the peroxisome proliferative-activated receptor alpha agonist fenofibrate in mice. J. Biol. Chem. 277:48051-48057.

39. Tenenbaum, A., et al. 2004. Peroxisome proliferatoractivated receptor ligand bezafibrate for prevention of type 2 diabetes mellitus in patients with coronary artery disease. Circulation. 109:2197-2202.

40. Li, A.C., et al. 2000. Peroxisome proliferator-activated receptor $\gamma$ ligands inhibit development of atherosclerosis in LDL receptor-deficient mice. J. Clin. Invest. 106:523-531.

41. Li, A.C., et al. 2004. Differential inhibition of macrophage foam-cell formation and atherosclerosis in mice by PPAR $\alpha, \beta / \delta$, and $\gamma$. J. Clin. Invest. 114:1564-1576. doi:10.1172/JCI200418730.

42. Hennuyer, N., et al. 2005. PPAR $\alpha$, but not PPAR $\gamma$, activators decrease macrophage-laden atherosclerotic lesions in a nondiabetic mouse model of mixed dyslipidemia. Arterioscler. Thromb. Vasc. Biol. 25:1897-1902.

43. [Anonymous]. 1978. A co-operative trial in the primary prevention of ischaemic heart disease using clofibrate. Report from the Committee of Principal Investigators. Br. Heart J. 40:1069-1118.

44. Oliver, M.F., Heady, J.A., Morris, J.N., and Cooper, J. 1980. W.H.O. cooperative trial on primary prevention of ischaemic heart disease using clofibrate to lower serum cholesterol: mortality follow-up. Report of the committee of principal investigators. Lancet. 316:379-385.

45. Oliver, M.F., Heady, J.A., Morris, J.N., and Cooper, J. 1984. W.H.O. cooperative trial on primary prevention of ischaemic heart disease with clofibrate to lower serum cholesterol: final mortality follow-up. Report of the committee of principal investigators. Lancet. 324:600-604.

46. Frick, M.H., et al. 1987. Helsinki Heart Study: primary-prevention trial with gemfibrozil in middleaged men with dyslipidemia. Safety of treatment, changes in risk factors, and incidence of coronary heart disease. N. Engl. J. Med. 317:1237-1245.

47. Rubins, H.B., et al. 1999. Gemfibrozil for the secondary prevention of coronary heart disease in men with low levels of high-density lipoprotein cholesterol. Veterans Affairs High-Density Lipoprotein Cholesterol Intervention Trial Study Group.
N. Engl.J. Med. 341:410-418.

48. The BIP Study Group. 2000. Secondary Prevention by raising HDL cholesterol and reducing triglycerides in patients with coronary artery disease. The Bezafibrate Infarction Prevention (BIP) study. Circulation. 102:21-27.

49. The FIELD study investigators. 2005. Effects of long-term fenofibrate therapy on cardiovascular events in 9,795 people with type 2 diabetes mellitus (the FIELD study): randomised clinical trial. Lancet. 366:1849-1861.

50. Dormandy, J.A., et al. 2005. Secondary prevention of macrovascular events in patients with type 2 diabetes in the PROactive Study (PROspective pioglitAzone Clinical Trial In macroVascular Events): a randomised controlled trial. Lancet. 366:1279-1289.

51. Zhang, H., et al. 2005. Collecting duct specific deletion of peroxisome proliferator-activated receptor blocks thiazolidinedione-induced fluid retention. Proc. Natl. Acad. Sci. U. S. A. 102:9406-9411.

52. Guan, Y., et al. 2005. Thiazolidinediones expand body fluid volume through PPARgamma stimulation of ENaC-mediated renal salt absorption. Nat. Med. 11:861-866.

53. Semenkovich, C.F. 2005. TZDs and diabetes: testing the waters. Nat. Med. 11:822-824.

54. Nissen, S.E., Wolski, K., and Topol, E.J. 2005. Effect of muraglitazar on death and major adverse cardiovascular events in patients with type 2 diabetes mellitus. JAMA. 294:2581-2586.

55. UK Prospective Diabetes Study (UKPDS) Group. 1998. Effect of intensive blood-glucose control with metformin on complications in overweight patients with type 2 diabetes (UKPDS 34). Lancet. 352:854-865.

56. Pi-Sunyer, F.X., et al. 2006. Effect of rimonabant, a cannabinoid-1 receptor blocker, on weight and cardiometabolic risk factors in overweight or obese patients. RIO-North America: a randomized controlled trial. JAMA. 295:761-775.

57. MacLennan, S.J., Reynen, P.H., Kwan, J., and Bonhaus, D.W. 1998. Evidence for inverse agonism of SR141716A at human recombinant cannabinoid CB1 and CB2 receptors. Br. J. Pharmacol. 124:619-622.

58. Steffens, S., et al. 2005. Low dose oral cannabinoid therapy reduces progression of atherosclerosis in mice. Nature. 434:782-786.

59. Gosling, J., et al. 1999. MCP-1 deficiency reduces susceptibility to atherosclerosis in mice that overexpress human apolipoprotein B. J. Clin. Invest. 103:773-778.

60. Boring, L., Gosling, J., Cleary, M., and Charo, I.F. 1998. Decreased lesion formation in CCR2-/- mice reveals a role for chemokines in the initiation of atherosclerosis. Nature. 394:894-897.

61. Smith, J.D., et al. 1995. Decreased atherosclerosis in mice deficient in both macrophage colony-stimulating factor (op) and apolipoprotein E. Proc. Natl. Acad. Sci. U. S. A. 92:8264-8268.

62. Haj, F.G., Zabolotny, J.M., Kim, Y.B., Kahn, B.B., and Neel, B.G. 2005. Liver-specific protein-tyrosine phosphatase 1B (PTP1B) re-expression alters glucose homeostasis of PTP1B-/- mice. J. Biol. Chem. 280:15038-15046.

63. Heinonen, K.M., Dube, N., Bourdeau, A., Lapp, W.S., and Tremblay, M.L. 2006. Protein tyrosine phosphatase $1 \mathrm{~B}$ negatively regulates macrophage development through CSF-1 signaling. Proc. Natl. Acad. Sci. U. S. A. 103:2776-2781.

64. Utiger, R.D. 1995. Altered thyroid function in nonthyroidal illness and surgery. To treat or not to treat? N. Engl. J. Med. 333:1562-1563.

65. Brent, G.A., and Hershman, J.M. 1986. Thyroxine therapy in patients with severe nonthyroidal illnesses and low serum thyroxine concentration. J. Clin. Endocrinol. Metab. 63:1-8.

66. Gardner, D.F., Kaplan, M.M., Stanley, C.A., and
Utiger, R.D. 1979. Effect of triiodothyronine replacement on the metabolic and pituitary responses to starvation. N. Engl.J. Med. 300:579-584.

67. Hotamisligil, G.S., and Spiegelman, B.M. 1994. Tumor necrosis factor alpha: a key component of the obesity-diabetes link. Diabetes. 43:1271-1278.

68. Schreyer, S.A., Peschon, J.J., and LeBoeuf, R.C. 1996. Accelerated atherosclerosis in mice lacking tumor necrosis factor receptor p55. J. Biol. Chem. 271:26174-26178.

69. Gerbod-Giannone, M.-C., et al. 2006. TNFalpha induces ABCA1 through NF-kappaB in macrophages and in phagocytes ingesting apoptotic cells. Proc. Natl. Acad. Sci. U. S. A. 103:3112-3117.

70. Kanters, E., et al. 2003. Inhibition of NF- $\mathrm{KB}$ activation in macrophages increases atherosclerosis in LDL receptor-deficient mice. J. Clin. Invest. 112:1176-1185. doi:10.1172/JCI200318580.

71. Evans, J.L., Goldfine, I.D., Maddux, B.A., and Grodsky, G.M. 2002. Oxidative stress and stress-activated signaling pathways: a unifying hypothesis of type 2 diabetes. Endocr. Rev. 23:599-622.

72. Ugi, S., Sharma, P.M., Ricketts, W., Imamura, T., and Olefsky, J.M. 2002. Phosphatidylinositol 3kinase is required for insulin-stimulated tyrosine phosphorylation of Shc in 3T3-L1 adipocytes. J. Biol. Chem. 277:18592-18597.

73. Shi, K., et al. 2004. Protein-tyrosine phosphatase $1 \mathrm{~B}$ associates with insulin receptor and negatively regulates insulin signaling without receptor internalization. J. Biochem. (Tokyo). 136:89-96.

74. Whiteman, E.L., Chen, J.J., and Birnbaum, M.J. 2003. Platelet-derived growth factor (PDGF) stimulates glucose transport in 3T3-L1 adipocytes overexpressing PDGF receptor by a pathway independent of insulin receptor substrates. Endocrinology. 144:3811-3820.

75. Boucher, P., Gotthardt, M., Li, W.P., Anderson, R.G., and Herz, J. 2003. LRP: role in vascular wall integrity and protection from atherosclerosis. Science. 300:329-332.

76. Baumgartl, J., et al. 2006. Myeloid lineage cellrestricted insulin resistance protects apolipoproteinE-deficient mice against atherosclerosis. Cell Metab. 3:247-256.

77. Han, S., et al. 2006. Macrophage insulin receptor deficiency increases ER stress-induced apoptosis and necrotic core formation in advanced atherosclerotic lesions. Cell Metab. 3:257-266.

78. Camps, M., et al. 2005. Blockade of PI3Kgamma suppresses joint inflammation and damage in mouse models of rheumatoid arthritis. Nat. Med. 11:936-943.

79. Barber, D.F., et al. 2005. PI3Kgamma inhibition blocks glomerulonephritis and extends lifespan in a mouse model of systemic lupus. Nat. Med. 11:933-935.

80. Mason, P.A., Matheson, E.C., Hall, A.G., and Lightowlers, R.N. 2003. Mismatch repair activity in mammalian mitochondria. Nucleic Acids Res. 31:1052-1058.

81. Patti, M.E., et al. 2003. Coordinated reduction of genes of oxidative metabolism in humans with insulin resistance and diabetes: potential role of PGC1 and NRF1. Proc. Natl. Acad. Sci. U. S. A. 100:8466-8471.

82. Petersen, K.F., Dufour, S., Befroy, D., Garcia, R., and Shulman, G.I. 2004. Impaired mitochondrial activity in the insulin-resistant offspring of patients with type 2 diabetes. N. Engl. J. Med. 350:664-671.

83. Du, X., et al. 2006. Insulin resistance reduces arterial prostacyclin synthase and eNOS activities by increasing endothelial fatty acid oxidation. J. Clin. Invest. 116:1071-1080. doi:10.1172/JCI23354.

84. Ballinger, S.W., et al. 2002. Mitochondrial integrity and function in atherogenesis. Circulation. 106:544-549.

85. Levin, M., et al. 2003. Mapping of ATP, glucose, glyco- 
gen, and lactate concentrations within the arterial wall. Arterioscler. Thromb. Vasc. Biol. 23:1801-1807.

86. Santerre, R.F., Nicolosi, R.J., and Smith, S.C. 1974 Respiratory control in preatherosclerotic susceptible and resistant pigeon aortas. Exp. Mol. Pathol. 20:397-406.

87. Smith, E.B. 1962. Lipids carried by $\mathrm{S}_{\mathrm{f}}$ 0-12 lipoprotein in normal and hypercholesterolaemic serum. Lancet. 2:530-534.

88. Klein, P.D., and Johnson, R.M. 1954. Phosphorus metabolism in unsaturated fatty acid-deficient rats. J. Biol. Chem. 211:103-110.

89. Cornwell, D.G., and Panganamala, R.V. 1981. Atherosclerosis: an intracellular deficiency in essential fatty acids. Prog. Lipid Res. 20:365-376.

90. Bernal-Mizrachi, C., et al. 2005. Vascular respiratory uncoupling increases blood pressure and atherosclerosis. Nature. 435:502-506

91. Wilson, F.H., et al. 2004. A cluster of metabolic defects caused by mutation in a mitochondrial tRNA. Science. 306:1190-1194.

92. Heaton, J.M. 1972. The distribution of brown adipose tissue in the human. J. Anat. 112:35-39.

93. Tordjman, K., et al. 2001. PPAR $\alpha$ deficiency reduces insulin resistance and atherosclerosis in apoE null mice. J. Clin. Invest. 107:1025-1034.

94. Bernal-Mizrachi, C., et al. 2003. Dexamethasone induction of hypertension and diabetes is PPAR $\alpha$ dependent in LDL receptor null mice. Nat. Med. 9:1069-1075

95. Nisoli, E., et al. 2005. Calorie restriction promotes mitochondrial biogenesis by inducing the expression of eNOS. Science. 310:314-317.

96. Spees, J.L., Olson, S.D., Whitney, M.J., and Prockop, D.J. 2006. Mitochondrial transfer between cells can rescue aerobic respiration. Proc. Natl. Acad. Sci. U. S. A. 103:1283-1288.

97. Lu, T., et al. 2004. Gene regulation and DNA damage in the ageing human brain. Nature. 429:883-891.

98. DeBusk, F.L. 1972. The Hutchinson-Gilford progeria syndrome. Report of 4 cases and review of the literature. J. Pediatr. 80:697-724.

99. Rosenbloom, A.L., et al. 1983. Progeria: insulin resistance and hyperglycemia. J. Pediatr. 102:400-402.

100.Varga, R., et al. 2006. Progressive vascular smooth muscle cell defects in a mouse model of Hutchinson-Gilford progeria syndrome. Proc. Natl. Acad. Sci.
U. S. A. 103:3250-3255.

101. Liu, B., et al. 2005. Genomic instability in laminopathy-based premature aging. Nat. Med. 11:780-785

102.Fong, L.G., et al. 2006. A protein farnesyltransferase inhibitor ameliorates disease in a mouse model of progeria. Science. 311:1621-1623.

103. Gray, M.D., et al. 1997. The Werner syndrome protein is a DNA helicase. Nat. Genet. 17:100-103.

104.Yamada, K., Ikegami, H., Yoneda, H., Miki, T., and Ogihara, T. 1999. All patients with Werner's syndrome are insulin resistant, but only those who also have impaired insulin secretion develop overt diabetes. Diabetes Care. 22:2094-2095.

105.Epstein, C.J., Martin, G.M., Schultz, A.L., and Motulsky, A.G. 1966. Werner's syndrome: a review of its symptomatology, natural history, pathologic features, genetics and relationship to the natura aging process. Medicine (Baltimore). 45:177-221.

106. Bakkenist, C.J., and Kastan, M.B. 2003. DNA damage activates ATM through intermolecular autophosphorylation and dimer dissociation. Nature. 421:499-506

107. Ihling, C., et al 1998 Co-expression of p53 and MDM2 in human atherosclerosis: implications for the regulation of cellularity of atherosclerotic lesions. J. Pathol. 185:303-312.

108.Martinet, W., Knaapen, M.W., De Meyer, G.R., Herman, A.G., and Kockx, M.M. 2001. Oxidative DNA damage and repair in experimental atherosclerosis are reversed by dietary lipid lowering. Circ. Res. 88:733-739.

109.Guevara, N.V., Kim, H.S., Antonova, E.I., and Chan, L. 1999. The absence of p53 accelerates atherosclerosis by increasing cell proliferation in vivo. Nat. Med. 5:335-339.

110. Van Vlijmen, B.J., et al. 2001. Macrophage p53 deficiency leads to enhanced atherosclerosis in $\mathrm{APOE}^{*} 3$ Leiden transgenic mice. Circ. Res. 88:780-786.

111.Licht, C.L., Stevnsner, T., and Bohr, V.A. 2003. Cockayne syndrome group B cellular and biochemical functions. Am. J. Hum. Genet. 73:1217-1239.

112. Ozcan, U., et al. 2004. Endoplasmic reticulum stress links obesity, insulin action, and type 2 diabetes. Science. 306:457-461.

113. Ricci, R., et al. 2004. Requirement of JNK2 for scavenger receptor A-mediated foam cell formation in atherogenesis. Science. 306:1558-1561.
114.Devries-Seimon, T., et al. 2005. Cholesterol-induced macrophage apoptosis requires ER stress pathways and engagement of the type A scavenger receptor. J. Cell Biol. 171:61-73.

115.Wang, D., Wei, Y., and Pagliassotti, M.J. 2006. Saturated fatty acids promote endoplasmic reticulum stress and liver injury in rats with hepatic steatosis. Endocrinology. 147:943-951.

116.Zhang, K., et al. 2006. Endoplasmic reticulum stress activates cleavage of CREBH to induce a systemic inflammatory response. Cell. 124:587-599.

117. The Diabetes Control and Complications Trial/ Epidemiology of Diabetes Interventions and Complications (DCCT/EDIC) Study Research Group. 2005. Intensive diabetes treatment and cardiovascular disease in patients with type 1 diabetes. N. Engl. J. Med. 353:2643-2653.

118.Lalla, E., et al. 2006. Periodontal changes in children and adolescents with diabetes: a case-control study. Diabetes Care. 29:295-299.

119.Beck, J.D., et al. 2001. Relationship of periodontal disease to carotid artery intima-media wall thickness: the Atherosclerosis Risk in Communities (ARIC) study. Arterioscler. Thromb. Vasc. Biol. 21:1816-1822.

120.Gibson, F.C., 3rd, et al. 2004. Innate immune recognition of invasive bacteria accelerates atherosclerosis in apolipoprotein E-deficient mice. Circulation. 109:2801-2806.

121. Backhed, F., et al. 2004. The gut microbiota as an environmental factor that regulates fat storage. Proc. Natl. Acad. Sci. U. S. A. 101:15718-15723.

122.Vikramadithyan, R.K., et al. 2005. Human aldose reductase expression accelerates diabetic atherosclerosis in transgenic mice.J. Clin. Invest. 115:2434-2443. doi:10.1172/JCI24819.

123. Ruef, J., et al. 2000. Involvement of aldose reductase in vascular smooth muscle cell growth and lesion formation after arterial injury. Arterioscler. Thromb. Vasc. Biol. 20:1745-1752.

124.Aprahamian, T., et al. 2004. Impaired clearance of apoptotic cells promotes synergy between atherogenesis and autoimmune disease. J. Exp. Med. 199:1121-1131.

125.van den Elzen, P., et al. 2005. Apolipoprotein-mediated pathways of lipid antigen presentation. Nature. 437:906-910. 